University of Nebraska - Lincoln

DigitalCommons@University of Nebraska - Lincoln

\title{
FUM13 Encodes a Short Chain Dehydrogenase/Reductase Required for C-3 Carbonyl Reduction during Fumonisin Biosynthesis in Gibberella moniliformis
}

\author{
Robert A. E. Butchko \\ USDA-ARS, butchkora@ncaur.usda.gov \\ Ronald D. Plattner \\ USDA-ARS \\ Robert H. Proctor \\ USDA-ARS
}

Follow this and additional works at: https://digitalcommons.unl.edu/usdaarsfacpub

Butchko, Robert A. E.; Plattner, Ronald D.; and Proctor, Robert H., "FUM13 Encodes a Short Chain Dehydrogenase/Reductase Required for C-3 Carbonyl Reduction during Fumonisin Biosynthesis in Gibberella moniliformis" (2003). Publications from USDA-ARS / UNL Faculty. 1577.

https://digitalcommons.unl.edu/usdaarsfacpub/1577

This Article is brought to you for free and open access by the U.S. Department of Agriculture: Agricultural Research Service, Lincoln, Nebraska at DigitalCommons@University of Nebraska - Lincoln. It has been accepted for inclusion in Publications from USDA-ARS / UNL Faculty by an authorized administrator of DigitalCommons@University of Nebraska - Lincoln. 


\title{
FUM13 Encodes a Short Chain Dehydrogenase/Reductase Required for C-3 Carbonyl Reduction during Fumonisin Biosynthesis in Gibberella moniliformis
}

\author{
Robert A. E. Butchko,* Ronald D. Plattner, and Robert H. Proctor \\ National Center for Agricultural Utilization Research, Agricultural Research Service, \\ U.S. Department of Agriculture, 1815 North University Street, Peoria, Illinois 61604-3999
}

\begin{abstract}
Fumonisins are polyketide-derived mycotoxins produced by the filamentous fungus Gibberella moniliformis (anamorph Fusarium verticillioides). Wild-type strains of the fungus produce predominantly four B-series fumonisins, designated $\mathrm{FB}_{1}, \mathrm{FB}_{2}, \mathrm{FB}_{3}$, and $\mathrm{FB}_{4}$. Recently, a cluster of 15 putative fumonisin biosynthetic genes (FUM) was described in G. moniliformis. We have now conducted a functional analysis of FUM13, a gene in the cluster that is predicted by amino acid sequence similarity to encode a short chain dehydrogenase/reductase (SDR). Mass spectrometric analysis of metabolites from FUM13 deletion mutants revealed that they produce approximately $10 \%$ of wild-type levels of B-series fumonisins as well as two previously uncharacterized compounds. NMR analysis revealed that the new compounds are similar in structure to $\mathrm{FB}_{3}$ and $\mathrm{FB}_{4}$ but that they have a carbonyl function rather than a hydroxyl function at carbon atom 3 (C-3). These results indicate that the FUM13 protein catalyzes the reduction of the C-3 carbonyl to a hydroxyl group and are the first biochemical evidence directly linking a FUM gene to a specific reaction during fumonisin biosynthesis. The production of low levels of $\mathrm{FB}_{1}, \mathrm{FB}_{2}, \mathrm{FB}_{3}$, and $\mathrm{FB}_{4}$, which have a $\mathrm{C}-3$ hydroxyl, by the $\mathrm{FUM} 13$ mutants suggests that $G$. moniliformis has an additional $C-3$ carbonyl reductase activity but that this enzyme functions less efficiently than the FUM13 protein.
\end{abstract}

KEYWORDS: Fumonisin; Gibberella moniliformis; Fusarium verticillioides; mycotoxin; gene cluster

\section{INTRODUCTION}

Fumonisins are polyketide-derived secondary metabolites produced by the filamentous fungus Gibberella moniliformis Wineland (anamorph Fusarium verticillioides (Sacc.) Nirenberg). These toxins, and others such as the AAL toxins of Alternaria alternata f. sp. lycopersici, have been described as sphingosine analogue mycotoxins because of the structural similarities they share with the sphingolipid intermediate sphingosine. In animal cells, fumonisins have been shown to inhibit sphingosine $\mathrm{N}$-acyltransferase thereby blocking sphingolipids biosynthesis (1). G. moniliformis causes ear and stalk rot of maize but can also be present in maize tissues without causing disease symptoms (2). Fumonisin induces leukoencephalomalacia, pulmonary edema, and cancer when ingested by horses, swine, and laboratory rodents, respectively $(3,4)$, and in some parts of the world where maize is a dietary staple, fumonisins have been implicated in human esophageal cancer (4).

Recently, a fumonisin biosynthetic gene cluster has been described on chromosome 1 in G. moniliformis (5). This cluster consists of 15 coregulated genes (FUM1 and FUM6 through FUM19). Amino acid sequence analysis indicated that 11 of

* To whom correspondence should be addressed. Tel: 309-681-6379. Fax: 309-681-6689. E-mail: butchkora@ncaur.usda.gov. the clustered genes are predicted to encode enzymes that catalyze biosynthetic reactions; two are predicted to encode transporters; and the two remaining genes are predicted to encode longevity assurance factors, which may have a self-protection function. To date, six FUM genes have been examined via disruption analysis. However, these analyses have not revealed the exact function of any of the genes. Disruptions of FUM1 (formerly FUM5), FUM6, and FUM8, which are predicted to encode a polyketide synthase, cytochrome P450 monooxygenase, and amino transferase, respectively, blocked fumonisin production but did not lead to the accumulation of identifiable fumonisin intermediates $(6,7)$. Disruption of FUM17 and FUM18, which are predicted to encode longevity assurance factors, had no effect on fumonisin production (5). Disruption of FUM19, which is predicted to encode an $\mathrm{ABC}$ transporter, resulted in a subtle alteration in the ratios of $\mathrm{FB}_{1}, \mathrm{FB}_{2}$, and $\mathrm{FB}_{3}$ produced (5).

FUM13 is predicted to encode a 369 -AA polypeptide with sequence similarity/identity to short chain dehydrogenases/ reductases (SDRs). SDRs include enzymes that catalyze the dehydrogenation or reduction of various substrates, such as alcohols, steroids, sugars, and aromatic compounds (8). Homology between any two SDRs is generally low. However, two regions are conserved. An amino-terminal nucleotide binding site (Thr-Gly- $\mathrm{X}_{2-3}-\mathrm{Gly}-\mathrm{X}_{1-2}-\mathrm{Gly}$ ) and the active site, which varies from a conserved triad of Ser, Tyr, and Lys residues to 

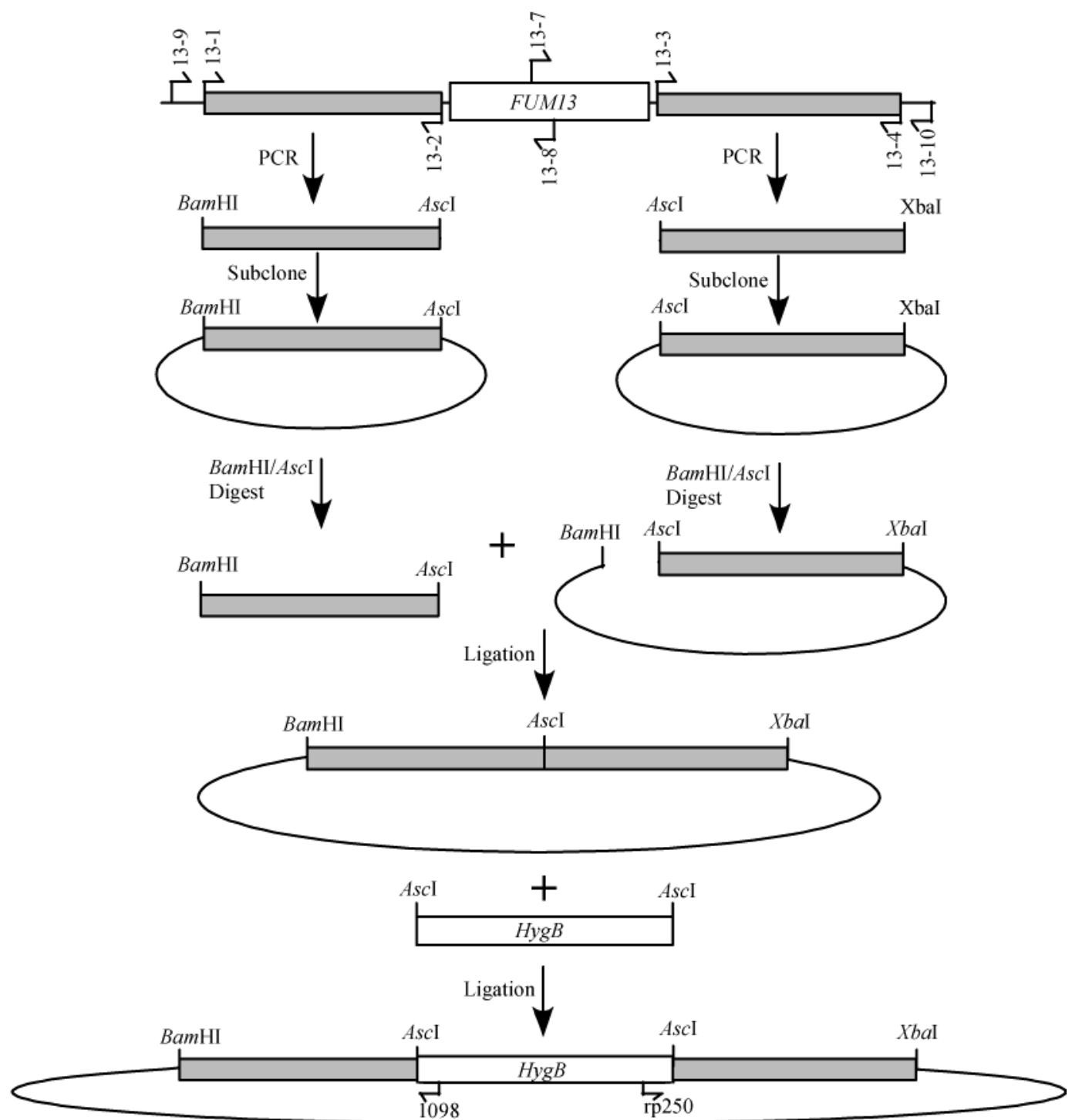

Figure 1. Engineering deletion vector pFUM13KOH. 13-1 through 13-4, 13-9 through 13-12, rp250, and 1098 indicate PCR primer sites. FUM13 indicates the location of the FUM13 coding region. HygB indicates the hygromycin resistance gene.

conservation of the Tyr residue only (8). In the current study, we characterized the function of the G. moniliformis FUM13 by gene deletion analysis.

\section{MATERIALS AND METHODS}

Strains and Media. G. moniliformis wild-type strain M-3125 was used throughout this study (9). The fungus was cultured on solid V8 juice medium for the production of conidia, in liquid GYEP (5\% glucose, $0.1 \%$ yeast extract, and $0.1 \%$ peptone) for genomic DNA preparation, and in cracked corn medium for analysis of fumonisin production $(7,10)$.

Fumonisin Analysis. G. moniliformis strains were initially screened by culturing on cracked corn for 2 weeks. Fumonisins were extracted with acetonitrile:water (1:1) as previously described (6). Extracts were diluted 100-fold with acetonitrile:water, and $10 \mu \mathrm{L}$ aliquots were analyzed by liquid chromatography/mass spectrometry (LC/MS) as previously described (11). For purification and isolation of fumonisins and related compounds, strains were cultured on cracked corn for 4 weeks and extracted as above. The extracts of six $50 \mathrm{~g}$ cultures were diluted with five volumes of water. This solution was fractionated using a preparative high-performance liquid chromatography (HPLC) column module (Ranin Instrument Co., Woburn, MA) at a flow rate of $5 \mathrm{~mL} /$ min using a linear solvent gradient from 20:80 (acetonitrile:water) to 50:50 over $120 \mathrm{~min}$ and a second wash gradient from 50:50 to 70:30 over $60 \mathrm{~min}$ followed by a final $60 \mathrm{~min}$ wash at $70: 30$. Fractions (50 $\mathrm{mL}$ ) were collected during the first gradient wash. Fractions were analyzed by LC/MS, and those containing similar fumonisin homologues were combined from several batches. Combined fractions were extracted with methylene chloride to remove unwanted components and chromatographed again following the protocol above to obtain fractions containing purified fumonisins for structural characterization by NMR. NMR spectra were obtained with a Bruker (Billerica, MA) Avance 400 spectrometer equipped with a $5 \mathrm{~mm}$ inverse broadband Z-gradient probe (13C NMR, $100 \mathrm{MHz}, 1 \mathrm{H}, 400 \mathrm{MHz}$ ).

Gene Deletion and Transformation. The FUM13 gene deletion vector, pFUM13KOH, was constructed by amplifying approximately $1 \mathrm{kbp}$ regions flanking both ends of the FUM13 coding region from cosmid cloned DNA following a polymerase chain reaction (PCR)based approach developed by Brown et. al (12). Primers 13-1 and 13-2 (Figure 1 and Table 1) were used to amplify the region upstream of the FUM13 start site. Primers 13-3 and 13-4 were used to amplify the region downstream of the FUM13 stop codon. Each primer included a restriction enzyme site (Table 1) that was used in subsequent subcloning steps. Primer 13-1 incorporated a BamHI site, primers 13-2 and 13-3 incorporated $A s c \mathrm{I}$ sites, and primer 13-4 incorporated an $\mathrm{XbaI}$ site. Figure 1 shows the successive subcloning steps. The PCR products were subcloned into plasmid vector pT7-Blue (Novagen). The BamHI/ AscI fragment containing the upstream flanking region was subcloned into the vector containing the downstream flanking region. This created 
Table 1. PCR Primer Sequences Used in This Studya

\begin{tabular}{ll}
\hline name & \multicolumn{1}{c}{ sequence } \\
\hline $13-1$ & GACGGATCCATGCGCAGCGTACTACTCCG \\
13-2 & GACGGCGCGCCATAAGTAAGATGACCAACGTGAGGACT \\
$13-3$ & GACGGCGCGCCAGTACCTTGGCTCGTCTGC \\
$13-4$ & GACTCTAGACGATGAACAACTTTCCCG \\
$13-7$ & CAACGACCTTACCACTACA \\
$13-8$ & CGTCGAAATGTAGTGTAAG \\
$13-9$ & AAGGGTTACGCTGCTATCCC \\
$13-10$ & CGACGGAATATGCTAGTCTA \\
rp250 & CTGCTGCATTCCCATTCCCATCGT \\
1098 & ACCAAGCCTATGCCTACAGCATCC
\end{tabular}

${ }^{a}$ Italics indicate restriction endonuclease sites engineered for subcloning procedures. GGATCC, recognition sequence for BamHI; GGCGCGCC, recognition sequence for Ascl; and TCTAGA, recognition sequence for $X b a l$.

a vector containing the upstream and downstream flanking regions in the appropriate orientation separated by an $A s c \mathrm{I}$ site. Last, a $2.5 \mathrm{kbp}$ $A s c \mathrm{I}$ fragment containing the hygromycin B resistance gene $(\mathrm{HygB})$ (13) was subcloned into the AscI site of the FUM13 deletion vector. All PCR products were generated using $P f u$ polymerase (Stratagene), and their nucleotide sequences were determined to verify the absence of any inadvertent mutations. Vector pFUM13KOH was designed such that homologous recombination of the vector with regions upstream and downstream of the FUM13 coding region would result in replacement of the entire coding region with the $H y g B$ resistance gene.

Transformation of G. moniliformis strain M-3125 was carried out using the protoplast method previously described with circular plasmid DNA and the modifications noted below (6). Protoplasts were regenerated on a high osmotic medium $(0.1 \%$ yeast extract, $0.1 \%$ caseinenzyme hydrolysate, $0.8 \mathrm{M}$ sucrose, and $1.6 \%$ agar), and hygromycin resistant transformants were selected by overlaying with $1 \%$ water agar containing $300 \mu \mathrm{g} / \mathrm{mL}$ hygromycin $\mathrm{B}$. Putative transformants were subsequently transferred to YEPD $(0.3 \%$ yeast extract, $1 \%$ peptone, and $2 \%$ glucose) amended with $150 \mu \mathrm{g} / \mathrm{mL}$ hygromycin $\mathrm{B}$. To ensure that each transformant represented only a single strain, all transformants were regrown from a single conidium prior to nucleic acid and fumonisin analysis.

Nucleic Acid Analysis of Transformants. Genomic DNA, for use in PCR, was prepared from mycelia grown on V8 juice agar. The mycelium was scraped from the agar surface and placed in $250 \mu \mathrm{L}$ of extraction buffer $(200 \mathrm{mM}$ Tris, $\mathrm{pH} 8.0,250 \mathrm{mM} \mathrm{NaCl}, 25 \mathrm{mM}$ ethylenediaminetetraacetic acid (EDTA), $0.5 \%$ sodium dodecyl sulfate $(\mathrm{SDS}))$ in a $1.7 \mathrm{~mL}$ Eppendorf tube, ground with a micropestle, and incubated for $10 \mathrm{~min}$ at $75^{\circ} \mathrm{C}$. After the mixture was heated, $250 \mu \mathrm{L}$ of a 1:1 mixture of TRIS-saturated phenol:chloroform:isoamyl alcohol $(25: 24: 1)$ was added and the mixture was vortexed for $30 \mathrm{~s}$. The aqueous phase was separated by centrifugation and removed to a fresh tube. Genomic DNA was purified from this solution using UltraBind following the manufacture's directions (Mo Bio, Solana Beach, CA).

PCR primers were designed to allow the amplification of bands specific to both $5^{\prime}$ and $3^{\prime}$ recombination events. Primer pairs 13-9/ 13-8 and 13-10/13-7 were used to detect the presence of an intact wildtype FUM13 at the 5' and $3^{\prime}$ ends, respectively, of the FUM13 coding region. Primer pair 13-9/1098 was used to detect homologous recombination between the $1 \mathrm{~kb}$ region immediately upstream of the FUM13 coding region and the deletion vector. Likewise, primer pair 13-10/ rp250 was used to detect homologous recombination between the $1 \mathrm{~kb}$ region immediately downstream of the FUM13 coding region and the deletion vector. The position of each primer is shown in Figure 1, and the primer sequences are shown in Table 1.

Southern blots were performed using standard protocols (14) to confirm the deletion of the FUM13 coding region in transformants. High molecular weight genomic DNA was prepared with the DNeasy plant kit (Qiagen) from GYEP-grown mycelia. DNA of selected transformants was doubly digested with Xhol/HindIII. Digested DNA was electrophoresed and blotted to nylon membrane. The hybridization probe consisted of a $1381 \mathrm{bp} \mathrm{XhoI/HindIII} \mathrm{fragment} \mathrm{spanning} 779 \mathrm{bp}$ of the $5^{\prime}$ end of FUM13 plus 602 bp upstream of the start codon. DNA was labeled with ${ }^{32} \mathrm{P}$ using the RediprimeII kit (Amersham Pharmacia Biotech).

\section{RESULTS}

FUM13 Encodes a SDR. Preliminary RPS-BLAST (15) analysis of FUM13 and subsequent protein alignment compiled with DNAMAN software (Lynnon BioSoft) revealed that the predicted FUM13 protein shares significant similarity to SDRs. The amino acid identity between any two SDRs is typically low, between 10 and $30 \%(8)$. This is true for the predicted FUM13 protein, which shares from 14 to $25 \%$ identity with the four proteins to which it is most similar (Figure 2). The FUM13 protein has a putative $\mathrm{N}$-terminal nucleotide binding region at AA 12-18 and a putative active site Tyr residue at AA 119 (Figure 2). Alignment with the proteins shown in Figure 2 illustrates the diversity of the enzymatic reactions catalyzed by SDR proteins. A tblastn search using the FUM13 nucleotide sequence to search the translated database at NCBI reveals many new homologies to predicted protein sequences arising from the ever-growing database of ESTs. These proteins share significantly more sequence similarity/identity at the amino acid level than the proteins presented in Figure 2; however, there are no experimental data to support their function as dehydrogenases/reductases.

Deletion of $\boldsymbol{F U M 1 3}$. We generated deletion mutants of $G$. moniliformis FUM13 by transformation of wild-type strain

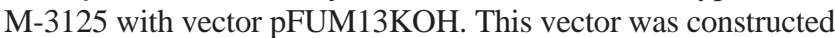
so that its recombination with homologous sequences on both sides of the FUM13 coding region would result in replacement of the coding region with the hygromycin resistance gene, $H y g B$. A PCR strategy was designed to distinguish between transformants with an intact wild-type FUM13 and those in which the FUM13 coding region had been deleted. Transformants were first assayed for loss of a PCR product indicative of the wildtype FUM13 and then for gain of a PCR product indicative of recombination between the vector and the FUM13 flanking sequences. PCR analysis of 35 hygromycin B resistant isolates recovered following transformation revealed that in two (GMT13-208 and GMT-13-224) the FUM13 coding region had been replaced by $H y g B$. The remainder had integrated only at one side of FUM13 or the vector integrations elsewhere in the genome. In subsequent Southern blot analyses, we included one representative transformant (GMT-13-212) that contained a single homologous integration event at the $5^{\prime}$ end of FUM13 and another representative transformant (GMT-13-201) that contained an ectopic integration of the vector elsewhere in the genome. Southern analysis confirmed the deletion of the FUM13 coding region in transformants GMT-13-208 and GMT-13-224 and the presence of the wild-type FUM13 band in transformants GMT-13-201 and GMT-13-212 (Figure 3). Replacement of the FUM13 coding region with $\operatorname{Hyg} B$ results in the loss of a 1381 bp band and the gain of a 3305 bp band (containing HygB) when hybridized with the 1381 bp XhoI/HindIII fragment described in the Materials and Methods.

Fumonisin Analysis. The two FUM13 deletion mutants, the 5 ' integration transformant, the ectopic integration transformant, and their wild-type progenitor strain, M-3125, were cultured on cracked corn to assess their ability to produce fumonisins. Initial LC/MS analysis of cracked maize culture extracts indicated that production of $\mathrm{FB}_{1}, \mathrm{FB}_{2}, \mathrm{FB}_{3}$, and $\mathrm{FB}_{4}$ was reduced by at least $90 \%$ in the FUM13 deletion mutants as compared to the wild-type strain and the other transformants. Fumonisin levels in uninoculated cracked corn were below detectable levels. 



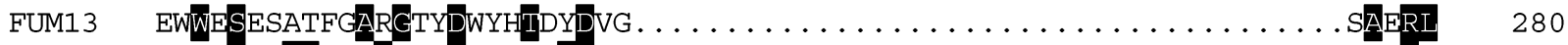

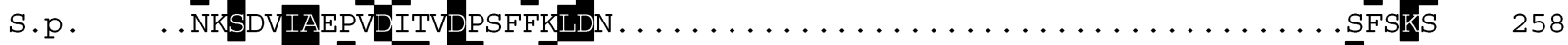

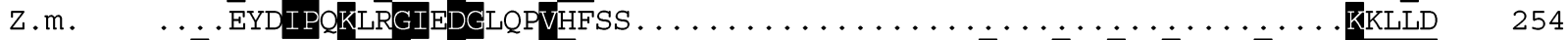

S.C. YFWALARTVWKADGHIDKHVIVLKRPVAICAGYLSEWVSKMLGKEPGLTPFRVKIVCAYRYHNIAKAKKI 276

A.t. KCTISVPFALSLGKIFQGFYTVLYPWLSKSW . . . . . . . LPQPLVLPAEVYKVGVTHYFSYLKAKEE 304

$\begin{array}{lll}\text { FUM13 } & \text { LG. RPFKCIEEOIYDSGSQVMEM . . . LKGMTTRSYN } & 312 \\ \text { S.p. } & \text { LG.FKYHSDEECYVDTAKKLWER . . . AEEFK } & 285 \\ \text { Z.m. } & \text { HG. FTFRYTVEDMFDAG. IRTCR. . . EKGLIPLATAGGVGSASLRTPGETDVTNG } & 304 \\ \text { S.c. } & \text { LGYTPRVGIEEGINKTLAWMDEGL } & 300 \\ \text { A.t. } & \text { LGYVPFKSSKEGMAATISYWQERKRRSLDGPTMFTWIAVTIGMSALFAAGWLPDIG } & 360\end{array}$

Figure 2. Amino acid comparison between FUM13 and four closely related SDR-like proteins. S.p., Schizosaccharomyces pombe putative cinnamoylCoA reductase (Gl:19114893); Z.m., Zea mays dihydrokaempferol 4-reductase (Gl:7427698); S.C., S. cerevisiae putative 3 $\beta$-hydroxysteroid dehydrogenase (Gl:1723793); A.t., Arabidopsis thaliana putative steroid dehydrogenase (Gl:2459443).

The LC/MS analysis of FUM13 deletion mutants also revealed that they produce several metabolites not seen in the wild-type strain (Figure 4). Relative amounts of these metabolites were approximately $60-80 \%$ of the total amount of fumonisins $\mathrm{B}_{1}, \mathrm{~B}_{2}$, and $\mathrm{B}_{3}$ from the wild-type. The two major metabolites observed in the deletion strains had protonated molecular ions at $\mathrm{m} / \mathrm{z} 704$ and 688. These molecular ions correspond to a loss of two mass units from $\mathrm{FB}_{2} / \mathrm{FB}_{3}$ and $\mathrm{FB}_{4}$, respectively, and are consistent with the presence of a carbonyl group at $\mathrm{C}-3$ of the fumonisin backbone. These two new metabolites were proposed to be 3-keto homologues of $\mathrm{FB}_{3}$ and $\mathrm{FB}_{4}$ based on their HPLC retention times. After the $m / z, 704$ metabolite was purified, it was hydrolyzed with $2 \mathrm{~N} \mathrm{KOH}$ in methanol. LC/MS analysis of the resulting mixture revealed a component that eluted slightly earlier than the expected retention time of hydrolyzed $\mathrm{FB}_{3}$ with a signal at $\mathrm{m} / \mathrm{z} 388$, which is consistent with the molecular weight of 387 expected for hydrolyzed 3-keto $\mathrm{FB}_{3}$. Similarly, the LC/MS of hydrolyzed products of the purified $\mathrm{m} / \mathrm{z} 688$ metabolite revealed a component with a signal at $\mathrm{m} / \mathrm{z} 374$, which is consistent with the expected molecular weight of hydrolyzed 3-keto $\mathrm{FB}_{4}$.
NMR analysis revealed that the proton spectrum of the putative 3-keto- $\mathrm{FB}_{3}$ homologue was identical to the $\mathrm{FB}_{3}$ spectrum except for three signals that were consistent with the presence of a C-3 carbonyl rather than a C-3 hydroxyl on the 3-keto homologue. First, the $\mathrm{FB}_{3}$ spectrum included a signal at $3.45 \mathrm{ppm}$ corresponding to the $\mathrm{C}-3$ hydrogen. The spectrum of the putative 3-keto homologue does not include this signal and, therefore, is consistent with the absence of a C-3 hydrogen. Second, the $\mathrm{FB}_{3}$ spectrum had a signal at $1.3 \mathrm{ppm}$ corresponding to the hydrogen atoms at $\mathrm{C}-1$. In the spectrum of the 3-keto homologue, this second signal was shifted to $1.49 \mathrm{ppm}$, a shift that was consistent with the $\mathrm{C}-1$ hydrogen atoms being $\beta$ to a carbonyl group rather than to a hydroxyl group. Finally, the $\mathrm{FB}_{3}$ spectrum included a signal at $3.1 \mathrm{ppm}$ corresponding to the hydrogen at C-2. In the spectrum of the 3-keto homologues, this third signal was shifted to $4.14 \mathrm{ppm}$, a shift that was consistent with the $\mathrm{C}-2$ hydrogen being adjacent to a carbon rather than to a hydroxyl carbon.

The carbon NMR spectra of $\mathrm{FB}_{3}$ (16) and the 3-keto- $\mathrm{FB}_{3}$ homologue were also identical except that the signal in the $\mathrm{FB}_{3}$ spectrum at $73.10 \mathrm{ppm}$, which corresponds to C-3, was shifted 


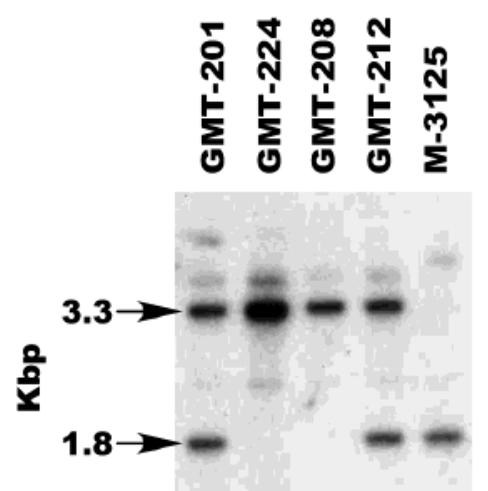

Figure 3. Southern analysis of G. moniliformis transformants. Genomic DNA was prepared from four transformants plus the wild-type progenitor strain as described in the Materials and Methods. Using a probe to the $5^{\prime}$ end of the gene, strain M-3125 shows the hybridization of the 1381-bp wild-type FUM13 band. Strains GMT-224 and GMT-208 contain deletions of FUM13 as indicated by the shift of the hybridizing band to $3305-\mathrm{bp}$ and the absence of the wild-type hybridization band. Strains GMT-201 and GMT-212 harbor ectopic copies of the deletion construct and thus have both the wild-type FUM13 hybridization band and the 3305-bp band.

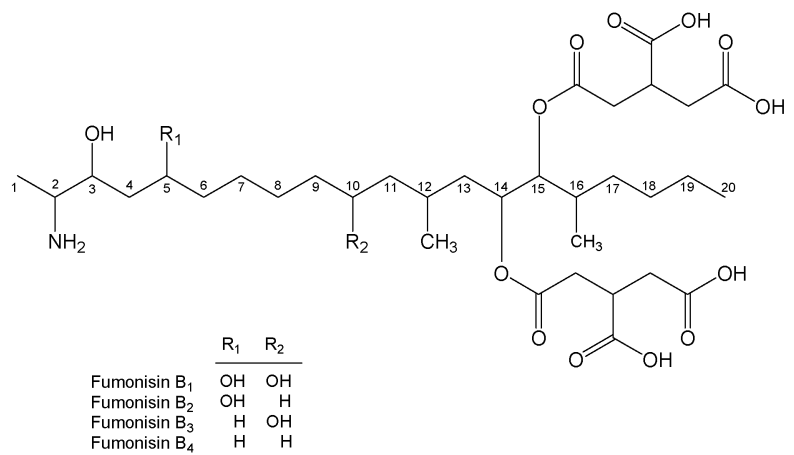

A.

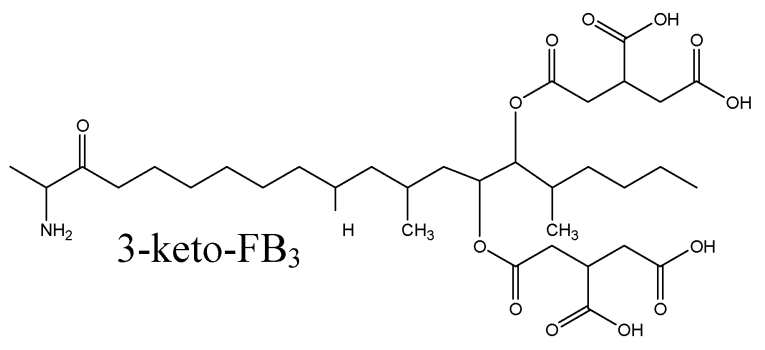

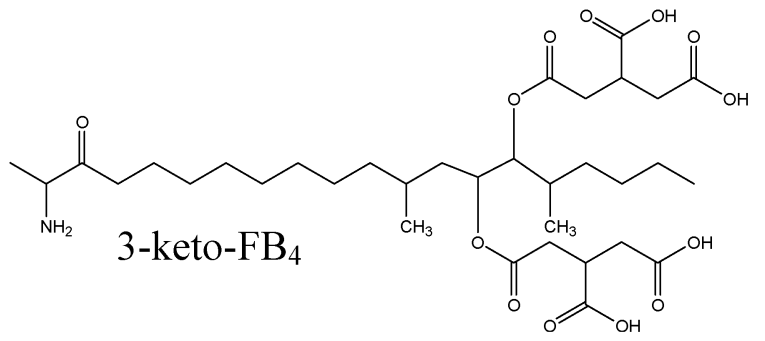

B.

Figure 4. (A) Major fumonisin homologues produced by wild-type strain M-3125. (B) Major fumonisin homologues produced by G. moniliformis FUM13 deletion mutants.

to $207.64 \mathrm{ppm}$ in the spectrum of the keto homologue. Table 2 lists the carbon shifts for fumonisin $\mathrm{B}_{3}(16,17)$ and the 3-keto$\mathrm{FB}_{3}$ homologue that accumulates in the FUM13 deletion mutant. This shift at carbon atom 3 is consistent with the presence of a carbonyl carbon rather than a hydroxyl carbon.

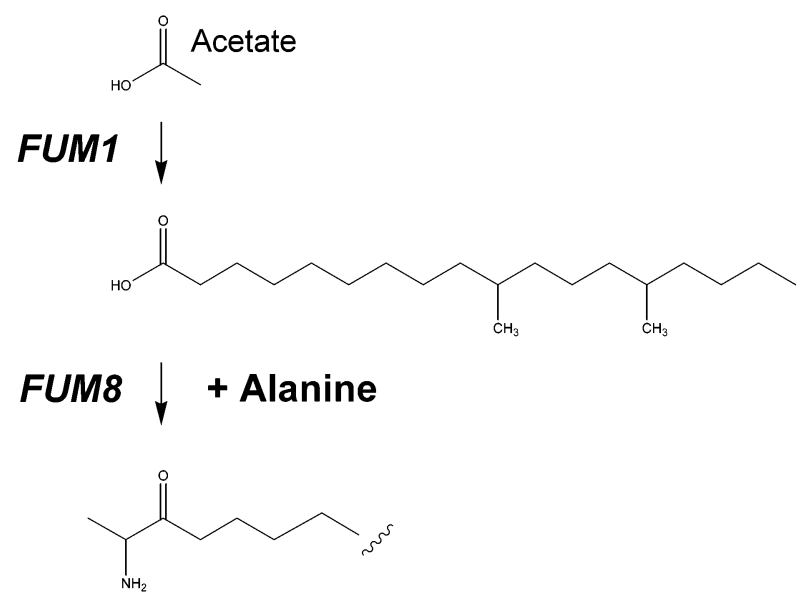

FUM13

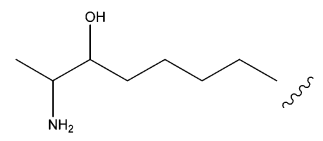

Figure 5. Proposed role of the FUM13 protein in the modification of the carbonyl end of the putative fumonisin polyketide during fumonisin biosynthesis.

Table 2. ${ }^{13}$ Carbon NMR Shift for 3-Keto Fumonisin $B_{3}$

\begin{tabular}{rrrrrr}
\hline carbon & $\mathrm{FB}_{3}$ & 3-keto-FB & carbon & $\mathrm{FB}_{3}$ & 3-keto-FB \\
\hline 1 & $15.9 \mathrm{q}$ & $20.7 \mathrm{q}$ & 18 & $30.7 \mathrm{t}$ & $30.0 \mathrm{t}$ \\
2 & $53.5 \mathrm{~d}$ & $44.6 \mathrm{~d}$ & 19 & $23.8 \mathrm{t}$ & $24.0 \mathrm{t}$ \\
3 & $73.1 \mathrm{~d}$ & $207.6 \mathrm{~d}$ & 20 & $14.4 \mathrm{q}$ & $15.8 \mathrm{q}$ \\
4 & $34.6 \mathrm{t}$ & $39.1 \mathrm{t}$ & 21 & $16.0 \mathrm{q}$ & $16.1 \mathrm{q}$ \\
5 & $26.2 \mathrm{t}$ & $24.2 \mathrm{t}$ & 22 & $20.6 \mathrm{q}$ & $20.8 \mathrm{q}$ \\
6 & $26.1 \mathrm{t}$ & $29.7 \mathrm{t}$ & 25 & $173.1 \mathrm{~s}$ & $173.3 \mathrm{~s}$ \\
7 & $26.8 \mathrm{t}$ & $30.6 \mathrm{t}$ & 26 & $36.6 \mathrm{t}$ & $39.2 \mathrm{t}$ \\
8 & $29.6 \mathrm{t}$ & $26.2 \mathrm{t}$ & 27 & $38.6 \mathrm{~d}$ & $39.4 \mathrm{~d}$ \\
9 & $39.3 \mathrm{t}$ & $39.2 \mathrm{t}$ & 28 & $36.1 \mathrm{t}$ & $36.8 \mathrm{t}$ \\
10 & $69.9 \mathrm{~d}$ & $70.0 \mathrm{~d}$ & 29 & $177.0 \mathrm{~s}$ & $176.7 \mathrm{~s}$ \\
11 & $44.5 \mathrm{t}$ & $44.7 \mathrm{t}$ & 30 & $175.2 \mathrm{~s}$ & $178.2 \mathrm{~s}$ \\
12 & $26.9 \mathrm{~d}$ & $30.0 \mathrm{~d}$ & 33 & $173.0 \mathrm{~s}$ & $173.2 \mathrm{~s}$ \\
13 & $36.4 \mathrm{t}$ & $37.1 \mathrm{t}$ & 34 & $36.6 \mathrm{t}$ & $36.8 \mathrm{t}$ \\
14 & $73.1 \mathrm{~d}$ & $73.0 \mathrm{~d}$ & 35 & $38.6 \mathrm{~d}$ & $39.1 \mathrm{~d}$ \\
15 & $78.8 \mathrm{~d}$ & $78.8 \mathrm{~d}$ & 36 & $36.1 \mathrm{t}$ & $37.1 \mathrm{t}$ \\
16 & $34.9 \mathrm{~d}$ & $33.1 \mathrm{~d}$ & 37 & $176.6 \mathrm{~s}$ & $176.2 \mathrm{~s}$ \\
17 & $33.1 \mathrm{t}$ & $33.1 \mathrm{t}$ & 38 & $175.0 \mathrm{~s}$ & $177.7 \mathrm{~s}$ \\
\hline
\end{tabular}

\section{DISCUSSION}

On the basis of the chemical structures of fumonisins and precursor feeding studies, fumonisin biosynthesis is predicted to include at least five groups of biochemical reactions: (i) synthesis of a linear polyketide with a single terminal carbonyl function and methyl groups at C-10 and C-14; (ii) condensation of the polyketide with alanine; (iii) reduction of the polyketide carbonyl to a hydroxyl; (iv) hydroxylation of 2-4 polyketide carbons; and (v) esterification of six-carbon tricarboxylic acids to two of the hydroxyls. In the current study, the accumulation of 3-keto homologues of $\mathrm{FB}_{3}$ and $\mathrm{FB}_{4}$ in FUM13 deletion mutants indicates that the SDR encoded by FUM13 catalyzes the reduction of the polyketide carbonyl to a hydroxyl during fumonisin biosynthesis (Figure 5). To our knowledge, this is the first evidence directly linking a gene in the fumonisin gene cluster with a specific biochemical reaction in fumonisin biosynthesis. The functions of most of the genes in the fumonisin gene cluster were predicted based on the results from BLAST sequence comparison (15). However, previous attempts to 
confirm the predicted functions of five of the genes (FUM6, FUM8, FUM17, FUM8, and FUM19) by gene disruption were not successful. For example, in the cases of FUM6 and FUM8, disruption blocked fumonisin production but did not result in accumulation of unusual fumonisin homologues that would provide evidence for the activities of the enzymes encoded by these genes $(6,7)$. By contrast, in this study, the accumulation of 3-keto $\mathrm{FB}_{3}$ and 3-keto $\mathrm{FB}_{4}$ homologues provides evidence that FUM13 encodes a C-3 carbonyl reductase.

The 3-keto fumonisin homologues produced by FUM13 deletion mutants provide further evidence that fumonisin biosynthesis uses a biosynthetic pathway analogous to that of the sphingolipid intermediate, sphinganine (18). Sphinganine synthesis begins with the condensation of palmitoyl-CoA and Ser to yield 3-ketosphinganine. The carbonyl of 3-ketosphinganine is then reduced to a hydroxyl to yield sphinganine. In Saccharomyces cerevisiae, a 3-ketosphinganine reductase encoded by TSC10 catalyzes this latter reaction and is predicted to be an SDR based on sequence analysis (19). Even though the TSC10 and FUM13 proteins are both SDRs and they catalyze analogous reactions, the two proteins are only about $10 \%$ identical over their entire length (data not shown).

Similarities between the structures and the biosynthesis of fumonisins and sphinganine suggest that the fumonisin C-3 oxygen is derived from acetate via a polyketide (5). This hypothesis is supported by mass spectrometric data on $\mathrm{FB}_{1}$ produced by $G$. moniliformis cultures in ${ }^{18} \mathrm{O}_{2}$ or $\mathrm{H}_{2}{ }^{18} \mathrm{O}$ feeding experiments carried out previously by Caldas et al. (20). When $\mathrm{H}_{2}{ }^{18} \mathrm{O}$ was fed to the cultures, up to seven ${ }^{18} \mathrm{O}$ atoms were incorporated into $\mathrm{FB}_{1}$. Upon hydrolysis, which cleaves the tricarballylic esters from the fumonisin backbone, the $\mathrm{FB}_{1}$ backbone lost all but one of the ${ }^{18} \mathrm{O}$ atoms. These results indicate that only one ${ }^{18} \mathrm{O}$ atom was attached directly to the fumonisin backbone and that the others were incorporated into the tricarballylic esters. In contrast, when ${ }^{18} \mathrm{O}_{2}$ was fed to the cultures, up to four ${ }^{18} \mathrm{O}$ atoms were incorporated into $\mathrm{FB}_{1}$. Upon hydrolysis, the $\mathrm{FB}_{1}$ backbone retained all four ${ }^{18} \mathrm{O}$ atoms. Although the Caldas et al. paper did not state it, the data presented (20) are most consistent with four of the five oxygen atoms attached directly to the $\mathrm{FB}_{1}$ backbone being derived from ${ }^{18} \mathrm{O}_{2}$ and the fifth being derived from $\mathrm{H}_{2}{ }^{18} \mathrm{O}$. We propose that the $\mathrm{C}-3$ oxygen is derived from $\mathrm{H}_{2}{ }^{18} \mathrm{O}$. C-3 of the fumonisin backbone corresponds to $\mathrm{C}-1$ of the polyketide precursor. In nascent polyketides, the $\mathrm{C}-1$ position typically has a carbonyl function that corresponds to the carbonyl function of the final acetate incorporated into a polyketide. If in the feeding studies described by Caldas et al. (20) the ${ }^{18} \mathrm{O}$ atom from $\mathrm{H}_{2}{ }^{18} \mathrm{O}$ was incorporated into acetate (e.g., via exchange of oxygen between water and carboxylic acid), it could be incorporated into the polyketide precursor of fumonisins via the activity of the polyketide synthase encoded by FUM1 (6). In contrast, the oxygen atoms at C-5, C-10, C-14, and C-15 of the fumonisin backbone could be derived from $\mathrm{O}_{2}$ by the activities of the monooxygenases (FUM6, FUM12, and FUM15) and dioxygenase (FUM9) encoded by the fumonisin gene cluster (5). These oxygenases utilize $\mathrm{O}_{2}$ to catalyze the formation of hydroxyl functions. This seems likely for the C-10 and C-14 oxygen atoms because they do not correspond to acetate carbonyls and therefore should be added to the fumonisin backbone after it is formed. Likewise, the C-5 oxygen is absent in $\mathrm{FB}_{3}$ and $\mathrm{FB}_{4}$ and therefore is also most likely added to the backbone after it is formed.

Although the FUM13 protein is most likely to catalyze the reduction of C-3 carbonyl of fumonisins in G. moniliformis, it is not essential for fumonisin production. This was evident by the production of low levels of $\mathrm{FB}_{1}, \mathrm{FB}_{2}, \mathrm{FB}_{3}$, and $\mathrm{FB}_{4}$ in the FUM13 deletion mutants. It is possible that these C-3-hydroxylated fumonisins are produced in the deletion mutants because of a partial redundancy of FUM13. That is, G. moniliformis may produce another enzyme(s) with the same activity as FUM13. Fumonisin production by FUM17, FUM18, and FUM19 disruption mutants indicates that these genes may also have redundant functions (5). Nevertheless, the low levels of C-3-hydroxylated fumonisins produced by the FUM13 mutants indicate that if a second enzyme with $\mathrm{C}-3$ carbonyl reductase activity exists, its activity is less than that of the FUM13 protein. A possible candidate for a second enzyme with this activity is 3-ketosphinganine reductase (19). As noted above, the carbonyl reduction of 3-ketosphinganine is analogous to the C-3 carbonyl reduction during fumonisin biosynthesis. Although a pathway for sphingolipid biosynthesis has not been described in $G$. moniliformis, it is likely that the fungus produces these lipids and has a TSC10 homologue because other Fusarium species produce sphingolipids (21).

The accumulation of 3-keto homologues of $\mathrm{FB}_{3}$ and $\mathrm{FB}_{4}$ but not the equivalent $\mathrm{FB}_{1}$ and $\mathrm{FB}_{2}$ homologues in cultures of FUM13 deletion mutants suggests that during fumonisin biosynthesis the C-3 carbonyl reduction must occur before the C-5 hydroxylation. The $\mathrm{C}-5$ hydroxyl is absent in $\mathrm{FB}_{3}, \mathrm{FB}_{4}$, and their 3-keto homologues but present in $\mathrm{FB}_{1}$ and $\mathrm{FB}_{2}$. If the $\mathrm{C}-5$ hydroxylation could occur before the $\mathrm{C}-3$ carbonyl reduction, FUM13 mutants would be expected to accumulate 3-keto homologues of $\mathrm{FB}_{1}$ and $\mathrm{FB}_{2}$ along with those of $\mathrm{FB}_{3}$ and $\mathrm{FB}_{4}$. In contrast, the $\mathrm{C}-10$ position of the fumonisin backbone can be hydroxylated independently of C-3 carbonyl reduction. This is evident because the only structural difference between the $3-\mathrm{ketoFB}_{3}$ and the 3 -ketoFB ${ }_{4}$ is the $\mathrm{C}-10$ hydroxyl; it is present in $3-\mathrm{ketoFB}_{3}$ and absent in $3-\mathrm{ketoFB}_{4}$. These findings are consistent with precursor feeding experiments that indicated that the $\mathrm{C}-10$ hydroxylation occurs earlier in fumonisin biosynthesis and that the C-5 hydroxylation occurred late in the biosynthesis (22).

Over the past decade, it has become evident that genes involved in the biosynthesis of a given fungal secondary metabolite tend to be clustered into groups of coregulated genes. Gene clusters have been described for mycotoxin biosynthetic pathways as well as for antibiotic biosynthetic and metabolite utilization pathways in fungi $(23,24)$. The description and characterization of these gene clusters have facilitated elucidation of the biochemical pathways for the corresponding metabolites and provided insight into the regulatory mechanisms of metabolite production or utilization $(12,23,25)$. The recent description of a fumonisin biosynthetic gene cluster in $G$. moniliformis (5) has allowed us to further characterize the biochemical pathway leading to the formation of fumonisins. FUM13, predicted to encode a SDR, is part of this biosynthetic gene cluster in G. moniliformis and through deletion analysis has been shown to be involved in fumonisin biosynthesis. Currently, we are disrupting the remaining genes in the FUM gene cluster to determine their functions in fumonisin biosynthesis. These studies should also provide further insight into the sequence of biochemical reactions that lead to the formation of fumonisins.

\section{ACKNOWLEDGMENT}

We acknowledge Marcie L. Moore, Deborah S. Shane, and Stephanie N. Folmar for technical assistance, David Weisleder 
for NMR analysis, and Anne E. Desjardins for critical evaluation of the manuscript.

\section{LITERATURE CITED}

(1) Wang, E.; Norred, W. P.; Bacon, C. W.; Riley, R. T.; Merrill, A. H., Jr. Inhibition of sphingolipid biosynthesis by fumonisins: implications for diseases associated with Fusarium moniliforme. J. Biol. Chem. 1991, 266, 14486-14490.

(2) Munkvold, G. P.; Desjardins, A. E. Fumonisins in maize: can we reduce their occurrence? Plant Dis. 1997, 81, 556-565.

(3) Howard, P. C.; Eppley, R. M.; Stack, M. E.; Warbritton, A.; Voss, K. A.; Lorentzen, R. J.; Kovach, R. M.; Bucci, T. J. Fumonisin B1 carcinogenicity in a two-year feeding study using F344 rats and B6C3F1 mice. Environ. Health Perspect. 2001, 109 S2, 277-282.

(4) Marasas, W. F. Discovery and occurrence of the fumonisins: a historical perspective. Environ. Health Perspect. 2001, 109 S2, 239-243.

(5) Proctor, R. H.; Brown, D. W.; Plattner, R. D.; Desjardins, A. E. Coexpression of fifteen contiguous genes delineates a fumonisin biosynthetic gene cluster in Gibberella moniliformis. Fungal Genet. Biol. 2003, 38, 237-249.

(6) Proctor, R. H.; Desjardins, A. E.; Plattner, R. D.; Hohn, T. M. A polyketide synthase gene required for biosynthesis of fumonisin mycotoxins in Gibberella fujikuroi mating population A. Fungal Genet. Biol. 1999, 27, 100-112.

(7) Seo, J.-A.; Proctor, R. H.; Plattner, R. D. Characertization of four clustered and coregulated genes associated with fumonisin biosynthesis in Fusarium verticillioides. Fungal Genet. Biol. 2001, 34, 155-165.

(8) Jornvall, H.; Persson, B.; Krook, M.; Atrian, S.; Gonzalez-Duarte, R.; Jeffery, J.; Ghosh, D. Short-chain dehydrogenases/reductases (SDR). Biochemistry 1995, 34, 6003-6013.

(9) Leslie, J. F.; Plattner, R. D.; Desjardins, A. E.; Klittich, C. J. R. Fumonisin B1 production by strains from different mating populations of Gibberella fujikuroi (Fusarium sections Liseola). Mycotoxicology 1992, 82, 341-345.

(10) Desjardins, A. E.; Plattner, R. D.; Proctor, R. H. Linkage among genes responsible for fumonisin biosynthesis in Gibberella fujikuroi mating population A. Appl. Environ. Microbiol. 1996, 62, 2571-2576.

(11) Plattner, R. D.; Wiesleder, D.; Poling, S. M. Analytical determination of fumonisins and other metabolites produced by Fusarium moniliforme and related species on corn. In Fumonisins in Food; Jackson, L. S., DeVeries, J. W., Bullerman, L. B., Eds.; Plenum: New York, 1996.

(12) Brown, D. W.; McCormick, S. P.; Alexander, N. J.; Proctor, R. H.; Desjardins, A. E. Inactivation of a cytochrome P-450 is a determinant of trichothecene diversity in Fusarium species. Fungal Genet. Biol. 2002, 36, 224-233.

(13) Turgeon, B. G.; Garber, R. C.; Yoder, O. C. Development of a fungal transformation system based on selection of sequences with promoter activity. Mol. Cell. Biol. 1987, 7, 3297-3305.
(14) Sambrook, J.; Fritsch, E. F.; Maniatis, T. Molecular Cloning, A Laboratory Manual; Cold Spring Harbor Press: Plainview, New York, 1989.

(15) Altschul, S. F.; Madden, T. L.; Schaffer, A. A.; Zhang, J.; Zhang, Z.; Miller, W.; Lipman, D. J. Gapped BLAST and PSI-BLAST: a new generation of protein database search programs. Nucleic Acids Res. 1997, 25, 3389-3402.

(16) Plattner, R. D.; Weisleder, D.; Shackelford, D. D.; Peterson, R.; Powell, R. G. A new fumonisin from solid cultures of Fusarium moniliforme. Mycopathologia 1992, 117, 23-28.

(17) Bezuidenhout, S. C.; Gelderblom, W. C. A.; Gorst-Allman, C. P.; Horak, R. M.; Marasas, W. F. O.; Spiteller, G.; Vleggaar, R. Structure elucidation of the fumonisins, mycotoxins from Fusarium moniliforme. J. Chem. Soc. Chem. Commun. 1988, 743-745.

(18) Powell, R. G.; Plattner, R. D. Fumonisins. In Alkaloids: Chemical and Biochemical Perspectives; Pelletier, S. W., Ed.; Pergamon Press: New York, 1995.

(19) Beeler, T.; Bacikova, D.; Gable, K.; Hopkins, L.; Johnson, C.; Slife, H.; Dunn, T. The Saccharomyces cerevisiae TSC10/ $Y B R 265 w$ gene encoding 3-ketosphinganine reductase is identified in a screen for temperature-sensative suppressors of the $\mathrm{Ca}^{2+}$ sensitive csg2 $\Delta$ mutant. J. Biol. Chem. 1998, 273, 30688-30694.

(20) Caldas, E. D.; Sadilkova, K.; Ward, B. L.; Jones, A. D.; Winter, C. K.; Gilchrist, D. G. Biosynthetic studies of fumonisin B1 and AAL toxins. J. Agric. Food Chem. 1998, 46, 4734-4743.

(21) Duarte, R. S.; Polycarpo, C. R.; Wait, R.; Hartmann, R.; Bergter, E. B. Structural characterization of neutral glycosphingolipids from Fusarium species. Biochim. Biophys. Acta 1998, 1390, 186-196.

(22) Proctor, R. H.; Desjardins, A. E.; Plattner, R. D. Biosynthetic and genetic relationships of B-series fumonisins produced by Gibberella fukikuroi mating population A. Nat. Toxins 1999, 7, 251-258.

(23) Keller, N. P.; Hohn, T. M. Metabolic pathway gene clusters in filamentous fungi. Fungal Genet. Biol. 1997, 21, 17-29.

(24) Woloshuk, C. P.; Prieto, R. Genetic organization and function of the aflatoxin B1 biosynthetic genes. FEMS Microbiol. Lett. 1998, 160, 169-176.

(25) Kennedy, J.; Auclair, K.; Kendrew, S. G.; Park, C.; Vederas, J. C.; Hutchinson, C. R. Modulation of polyketide synthase activity by accessory proteins during lovastatin biosynthesis. Science 1999, 284, 1368-1372.

Received for review December 6, 2002. Revised manuscript received March 10, 2003. Accepted March 10, 2003. Disclaimer: Names are necessary to report factually on available data; however, the USDA neither guarantees nor warrants the standard of these products, and the use of the name by the USDA implies no approval of the product to the exclusion of others that may also be suitable.

JF0262007 